\title{
Regime de Colaboração no financiamento da Educação Básica no Brasil: a experiência dos fundos contábeis em foco
}

\author{
Scheme to cooperate in the financing of Basic Education in \\ Brazil: the experience of accounting funds in focus
}

Edson Francisco Andrade*

Universidade Federal de Pernambuco

Resumo O presente texto discorre sobre a corresponsabilidade constitucional entre Estados, Municípios e União no que concerne à obrigação desses entes federados em garantir o atendimento de todos os níveis de educação escolar no País. Analisa-se, inicialmente, a concepção de Regime de Colaboração no contexto educacional brasileiro. Em seguida, tematiza-se a experiência da colaboração por meio dos fundos contábeis no Brasil. Por fim, destaca-se que a política de financiamento da educação que é levada a efeito pelos fundos contábeis tem contribuído para o provimento de uma agenda transitória para o setor, por conseguinte, faz-se imprescindível a consolidação de uma política de Estado que garanta investimento compatível com a totalidade do gasto com a Educação Básica no País.

PALAVRAS-CHAVE: Regime de Colaboração, Fundos contábeis, Financiamento da educação.

Abstract This paper focuses on the constitutional co-responsibility between states, municipalities and the Union regarding the duties of federal agencies to ensure the assistance to all levels of school education in Brazil. The concept of Collaboration Scheme in the Brazilian educational context is initially analyzed. Then, there is a discussion about the experience of collaboration through funds accounting in Brazil. Finally, it is emphasized that the policy of education funding that is promoted by the funds accounting has contributed to the provision of a transitional agenda for the sector. Therefore, it is essential to the consolidation of a state policy that guarantees investments compatible with the total expenses on basic education in Brazil.

KEYWORDS: Collaboration Scheme, Funds accounting, Financing of education. 


\section{Introdução}

As relações entre os três níveis de poder federado ainda são pautadas pelo exercício descendente do poder, manifesto através de decisões impostas pela esfera administrativa hierarquicamente mais elevada, ou da simples transferência de encargos, sem que haja a distribuição devida dos meios e recursos necessários. Pode-se afirmar que há, neste contexto de relações, uma situação em que a colaboração entre o Município, o Estado e a União é circunscrita à distribuição de matrículas da Educação Básica, sem que haja iniciativas para a elaboração de uma agenda programática de intervenções, acordada entre tais esferas, de modo a se explicitar o que e como serão levadas a efeito as ações necessárias à melhoria não somente do atendimento às demandas específicas de níveis e modalidades do ensino, mas, sobretudo, do provimento de meios que corroborem a conquista de resultados exitosos no que toca aos parâmetros almejados de qualidade social na educação.

Dessa afirmação pode-se inferir o entendimento de que, embora tenhamos o regime de colaboração preconizado no artigo 211 da Constituição Federal, e reafirmado no artigo $8^{\circ}$ da $\mathrm{LDB}$, fundando, portanto, o marco a partir do qual deverá ser estabelecida a corresponsabilidade entre Estados, Municípios e União, o que se constata é a indefinição do que cabe a cada instância de poder, sobretudo quando se refere à constituição de instrumentos que explicitem os papéis específicos de cada esfera administrativa, assim como as ações que serão pactuadas entre os sistemas de educação com o fim de atingir o atendimento de toda a Educação Básica no âmbito municipal.

Desta feita, justificamos a relevância deste estudo pela sua interlocução com o debate sobre o processo de descentralização da gestão educacional, sobretudo no que se refere à reflexão a respeito das possibilidades para a implementação do pacto federativo enquanto mecanismo de viabilização de políticas educacionais no âmbito do Poder Local. Esperamos que os resultados deste trabalho se tornem um importante subsídio para as municipalidades e os seus sujeitos sociais, no que concerne à construção orgânica de propostas (viáveis e concretas), integradas com a luta pela melhoria da qualidade do ensino nas escolas públicas e com a democratização da sociedade.

\section{A concepção de Regime de Colaboração no contexto educacional brasileiro}

A requisição e justificativa do Regime de Colaboração no Brasil têm sua plausibilidade fundamentada pela forte assimetria quanto à capacidade de autofinanciamento entre as suas esferas administrativas. A herança da desigualdade de distribuição de renda da população, as disparidades de potencial tributário entre as regiões, os graves problemas de discriminação étnica, além de outros, são alguns dos elementos que reforçam a necessidade de um pacto federativo que faça valer o sentido de sermos uma federação, que como já afirmamos, requer relação de reciprocidade entre suas partes constituintes. 
Conforme observa (ABRUCIO, 2010, p. 61), "a nomenclatura regime de colaboração só foi utilizada na educação, embora outros setores tenham incluído na Constituição a previsão de formas colaborativas". A rigor, para o bom atendimento dos demais direitos sociais (saúde, segurança, habitação, entre outros) têm-se semelhante necessidade de práticas colaborativas. Todos esses setores, como se sabe, atendem a um grande contingente que depende exclusivamente dos serviços públicos. Contudo, o sistema público de educação tem por obrigação atender cerca de 45 milhões de estudantes da Educação Básica diariamente.

Daí porque a explicitação da colaboração no campo educacional ser indicada pelo marco legal e defendida com grande ímpeto pelos sujeitos sociais que historicamente assumiram a defesa da educação pública, gratuita e com qualidade social indistinta para cidadãos inseridos na diversidade de condições socioeconômicas das unidades federativas. Ocorre que a Constituição Federal de 1988 apenas indica, ou recomenda, a regulamentação da colaboração (artigos 23 e 211). Recentemente, a Emenda Constitucional n ${ }^{\circ}$ 59/ 2009, modificou a redação do art. 211 da Carta Magna, que passa a vigorar em seu $\S 4^{\circ}$ o seguinte texto: "na organização de seus sistemas de ensino, a União, os Estados, o Distrito Federal e os Municípios definirão formas de colaboração, de modo a assegurar a universalização do ensino obrigatório".

Portanto, tem-se uma nova recomendação, dessa vez, para que no país haja formas de colaboração, sem avanços em relação ao que indica o artigo 23 da CF/1988, que definia a necessidade de uma lei complementar para regular a cooperação entre as esferas do poder federado. Essa omissão do parlamento brasileiro tem sido lembrada por um grande número de pesquisadores da área que tomam quase que unanimemente esse fato como fator preponderante das limitações quanto à equalização da qualidade do atendimento das demandas educacionais no País.

Dentre as constatações que se tornam enfáticas sobre essa matéria, fazse pertinente citar as conclusões de estudos de Abrucio (2010) de que essa lacuna normativa induziu um tipo de "municipalização" com negociações políticas entre os Estados e Municípios sem que houvesse uma arena institucional que mediasse o estabelecimento e cumprimento de critérios claros de repasse de funções, de modo que este processo dependeu muito mais do jogo político de gestores, portanto, para além da Política Educacional em si.

Pode-se adiantar que a perspectiva de colaboração que é desenhada através de termos regulamentadores firmados entre chefes do executivo não se coaduna ao princípio da descentralização político-administrativa que se vislumbra com a gestão sistêmica da educação, uma vez que as instâncias de participação democrática não têm parte na definição do que faz jus à colaboração. Esse contexto em que a ação colaborativa é deslocada do âmbito sistêmico para os gabinetes administrativos corresponde a um contexto político local marcado pela destituição do protagonismo do Poder Local em face da prevalência de práticas da barganha política protagonizadas por governos locais, configurando experiência tipicamente exemplar do municipalismo autárquico. 
Tal inflexão por que passa a colaboração nas práticas sociais tem sido, no entanto, velada por enunciados que reafirmam a imprescindibilidade da relação entre sistemas de educação, assim como realçam a legitimidade dos sujeitos coletivos na cogestão pública. Essa conformação discursiva ocorre, sobretudo, pela necessidade de obediência à ordem do discurso que tem na Constituição Federal de 1988 suas regras fundantes para que a gestão democrática da educação seja elevada ao status de formação discursiva a partir da qual os enunciados da participação social e da descentralização do poder decisório se impõem irrevogavelmente à colaboração $(\mathrm{CF} / 1988$, arts. $1,18,23$ e 60, § 4, I).

Cury (2005) salienta a imbricação da defesa pela colaboração no discurso pró-democratização que perpassou a constituinte nos anos 1980, reverberando no texto constitucional que promulga um regime normativo e político, plural e descentralizado no qual se cruzam novos mecanismos de participação social com um modelo institucional cooperativo que amplia o número de sujeitos políticos capazes de tomar decisões. Conforme análise do autor, é por essa razão que "a cooperação exige entendimento mútuo entre os entes federativos e a participação supõe a abertura de novas arenas públicas de deliberação e mesmo de decisão no que toca aos cidadãos" (CURY, 2005, p. 19).

É pertinente reconhecer que, ao longo dos anos 1990, a questão da colaboração é incorporada mais enfaticamente aos debates sobre a nova legislação pleiteada para a educação nacional, consumada, ainda que com seus limites e condicionantes pela LDB n ${ }^{\circ}$ 9.394/96. Destaque-se que esse dispositivo balizador da educação preconiza a operacionalização da cooperação como parte inerente às responsabilidades de cada esfera administrativa, ao dispor que a União incumbirse-á, em colaboração com os Estados, o Distrito Federal e os Municípios, de "estabelecer competências e diretrizes para a educação infantil, o ensino fundamental e o ensino médio, que nortearão os currículos e seus conteúdos mínimos, de modo a assegurar formação básica comum" (LDB/96, art. $9^{\circ}$, IV). Já os Estados assumem a incumbência da definição, juntamente com os Municípios, das "formas de colaboração na oferta do ensino fundamental, as quais devem assegurar a distribuição proporcional das responsabilidades, de acordo com a população a ser atendida e os recursos financeiros disponíveis em cada uma dessas esferas do Poder Público" (art. 10, II).

Com base nesse construto legal, Souza (2007) afirma que a ideia da interdependência e da corresponsabilidade é intrínseca ao federalismo cooperativo no campo educacional. Nesse sentido, o Regime de Colaboração pressupõe o compartilhamento de responsabilidades e encargos educacionais entre os entes federados, pois até mesmo as questões entendidas como de responsabilidade local (Municipal) se inserem, de algum modo, na esfera de responsabilidades do Estado e até da União, seja do ponto de vista da interdependência com as competências de coordenação, implementação e avaliação das políticas educacionais dessas instâncias, seja no que tange às responsabilidades fiscais e de financiamento, quando for o caso. 
Alguns exemplos práticos da colaboração entre os entes federados são imprescindíveis ao campo educacional, assim como destaca França (2002) ao mencionar pelo menos três aspectos, sendo eles: a) a divisão dos encargos; b) o estabelecimento de normas; e c) o planejamento da educação. O primeiro campo de ação refere-se ao compartilhamento quanto à garantia das condições objetivas dos trabalhos desenvolvidos pelos sistemas de educação, incluindose a disponibilidade de prédios, mediante a utilização conjunta de redes físicas e equipamentos necessários; estabelecimento de convênios sobre contratação e formação dos profissionais do magistério, previstos nos objetivos e metas do Plano Nacional de Educação (Lei n $\left.{ }^{\circ} 10.172 / 2001\right)$ e aqueles a serem inscritos no PNE (2011-2020); pacto orçamentário contemplando a destinação de provimento financeiro em conformidade com as demandas educacionais dos diferentes níveis de ensino.

Merece destaque, neste âmbito da colaboração, a distribuição proporcional das matrículas nos níveis de ensino, ajustada à demanda e à capacidade de atendimento de cada esfera, conforme dispõe a legislação $(\mathrm{CF}$, art. 211, § $4^{\circ}$; LDB, art. 10, II, e art. 75, § 2 ${ }^{\circ}$; Lei n ${ }^{\circ} 11.494 / 07$ - Fundeb). Ainda com base no aporte legal, Estados e Municípios podem celebrar convênios nos quais a transferência de responsabilidade por determinado número de matrículas seja acompanhada da correspondente transferência de recursos financeiros (Fundeb, art. 18).

O segundo aspecto diz respeito à exigência de que os acordos firmados perpassem os trâmites instituídos pelos órgãos normativos dos sistemas envolvidos. Trata-se de um movimento em que se presume, em primeiro lugar, a negociação sobre os interesses que serão priorizados, em segundo, a deliberação com os termos que melhor explicite a concordância entre as partes. Sobre essa matéria, é pertinente a observância do marco legal quando dispõe que a União, em colaboração com os Estados, o Distrito Federal e os Municípios, deve estabelecer competências e diretrizes para os currículos e conteúdos mínimos da Educação Básica (CF, art. 210 e LDB, art. $9^{\circ}$, IV); assim como os sistemas municipais de educação podem compactuar normas complementares entre si, através de apoio técnico a consórcios intermunicipais e colegiados regionais consultivos, quando necessários (PNE, Cap. V, item 11.3.2, meta 20).

O último tópico correlaciona-se, intrinsecamente, aos demais, pois faz menção à elaboração de planos conjuntos para a definição de metas e ações, bem como os mecanismos de avaliação assumidos pela parceria (LDB, art. $9^{\circ}, \mathrm{I}, \mathrm{V}$ e VI). Cabe menção ao texto legal quando preconiza que a União, em articulação com os Estados, o Distrito Federal, os Municípios e a sociedade civil, procederá avaliações periódicas da implementação do Plano Nacional de Educação (Lei n ${ }^{\circ}$ 10.172/01 - PNE, art. $3^{\circ}$ ); além de indicar que os Estados devem elaborar Planos Estaduais de Educação articulando-os com o Plano Nacional e integrando as ações de seus respectivos Municípios (DOURADO, 2011) e os Municípios devem organizar seus sistemas de educação integrando-os às políticas e planos educacionais da União e dos Estados (LDB, art. 11, I). 
Constata-se que, do ponto de vista formal, há uma significativa atenção ao regime de colaboração como estratégia, na área da educação, para nortear a relação entre a União, os Estados, o Distrito Federal e os Municípios. O que fica perceptível no contexto das práticas sociais que se desenvolvem entre os entes federados é que, apesar de todas as possibilidades mencionadas, tem-se, ainda, pouca cooperação efetiva entre estas instâncias de governo, situação que propicia o crescimento das desigualdades regionais e a ocorrência de ações superpostas ou de omissões nessa relação (SARI, 2007). Desta feita, há de se reconhecer que são muitos os desafios para a consolidação do regime de colaboração, dentre os quais, Sari (2007, p.5-6) sintetiza com os exemplos a seguir:

a) a falta de articulação para o atendimento à demanda da Educação Básica, em todas as suas etapas e modalidades;

b) a falta de apoio efetivo da União e dos Estados à organização dos sistemas municipais de ensino, conforme o previsto no PNE (Cap. V, item 11.3.2, meta 21);

c) a ausência de articulação entre os conselhos normativos das diversas instâncias, para a discussão das normas de interesse comum;

d) as dificuldades na integração de Estados e Municípios para a elaboração dos planos decenais de educação.

Com efeito, a concepção de federalismo em que se vislumbra ações pactuadas entre as esferas de poder suscita a discussão sobre a imprescindibilidade do papel das instâncias de mediação entre sociedade e Estado. Nesse sentido, consideramos pertinente a assertiva de (FRANÇA, 2002, p. 71-72), de que

uma condição importante para que o Regime de Colaboração se exerça no seu verdadeiro sentido é que os municípios instituam seus sistemas de ensino, pois estes dialogarão com os sistemas estaduais e com o da União sem subordinação ou hierarquia. Trata-se de uma relação entre iguais, que dividem, compartilham e trabalham em conjunto, segundo normas fixadas em legislação e regras acertadas em mesa de negociação, para chegar a deliberações compartilhadas.

O que se compreende por verdadeiro sentido da colaboração entre os entes federados tem particular acento sobre o que a autora apresenta como relação entre iguais. Sobre esse aspecto, é oportuno lembrar que todo o processo de municipalização que ocorre no Brasil demonstra o quanto se faz necessário a implementação do pacto federativo, significando a fixação das normas mediante as quais os entes de poder federado estariam obrigados a vincularem os recursos e as condições necessárias ao atendimento das demandas educacionais. As inovações com maior impacto nessa direção ocorreram no âmbito do financiamento da Educação Básica, razão pela qual tematizaremos as nuances desse processo na próxima seção. 


\section{A experiência da colaboração por meio dos fundos contábeis no Brasil}

No bojo das discussões sobre o novo marco legal brasileiro, o Congresso Nacional promulga, em setembro de 1996, a Emenda Constitucional n ${ }^{\circ} 14$ (EC $\left.\mathrm{n}^{\circ} 14\right)$, estabelecendo significativas modificações na política de financiamento da Educação Básica brasileira, ao instituir o Fundo de Manutenção e Desenvolvimento do Ensino Fundamental e de Valorização do Magistério (Fundeb).

Trata-se de um fundo de natureza estritamente contábil, não havendo, portanto, instituição de um órgão específico para operacionalizar sua administração, uma vez que sua finalidade é de apenas abrigar recursos financeiros para atender a saques em contas bancárias dos Estados, Distrito Federal e Municípios, sendo as cotas de cada um desses entes federados definidas e transferidas automaticamente com base no número de matrículas no Ensino Fundamental regular das respectivas redes de ensino.

A EC $\mathrm{n}^{\circ} 14$ previa investimentos voltados, especificamente, para a universalização do Ensino Fundamental, mediante a destinação de pelo menos 15\% dos recursos, vinculados a Manutenção e Desenvolvimento do Ensino, no âmbito de cada Estado e do Distrito Federal. Após uma década em que se verificaram avanços, mas também muitas perplexidades quanto ao reducionismo dos impactos desse fundo em relação aos persistentes desafios da educação pública no País, a essência da nova política é ratificada, com importantes ajustes, sobretudo para ampliar sua cobertura para toda a Educação Básica, através da Lei n ${ }^{\circ} 11.494$, de 20 de junho de 2007, que cria o Fundo de Manutenção e Desenvolvimento da Educação Básica e de Valorização dos Profissionais da Educação (Fundeb).

Previsto para durar 14 anos, o Fundeb pretende, na visão de seus proponentes, corrigir as falhas identificadas no decurso do Fundef, como a exclusão da Educação Infantil, EJA e Ensino Médio e de seus profissionais. Apresenta-se como perspectiva para o investimento dos fundos públicos em educação, a ratificação do ideário de divisão de responsabilidades entre os entes federativos quanto à oferta dos diferentes níveis de ensino, sob a expectativa de melhor distribuição dos recursos financeiros em âmbito nacional. $\mathrm{O}$ art. $8^{\circ}$ da Lei do Fundeb esclarece que a distribuição de recursos que compõem os Fundos, no âmbito de cada Estado e do Distrito Federal, dar-se-á entre o governo estadual e os de seus municípios, na proporção do número de alunos matriculados nas respectivas redes de Educação Básica pública presencial.

Percebe-se, portanto, que há uma inferência do ideário de regime de colaboração, estimando-se, desta feita, o exercício de ações articuladas entre as esferas administrativas, uma vez que os novos recursos têm sua lógica de distribuição em função do número de matrículas que os governos tiverem no seu âmbito de atuação prioritária, conforme o disposto nos $\S \S 2^{\circ}$ e $3^{\circ}$ do art. 211 da CF. Essa prerrogativa indica a necessária negociação no que diz respeito ao cumprimento das incumbências dos entes federativos com o atendimento da demanda da Educação 
Básica. $\mathrm{Na}$ prática, isso significa, por exemplo, que as matrículas municipais no Ensino Médio não serão levadas em conta na distribuição do Fundeb, porque as prefeituras não devem atuar, prioritariamente, no Ensino Médio, mas apenas na Educação Infantil e no Ensino Fundamental.

Faz-se pertinente considerar avanços, mas também registrar limites concernentes à efetivação do Fundeb até o momento, assim como a sua prospecção, considerando o que ainda está por acontecer no decurso de sua vigência, tema que vem sendo abordado de forma sistemática por pesquisadores da área (ABRUCIO, 2010; GURY, 2010; FRANÇA, 2009; PINTO, 2007; OLIVEIRA, 2007). Assim, é possível reconhecermos vantagens, como o fez França (2009), citando dois impactos deste Fundo para o financiamento da Educação Básica. O primeiro relaciona-se com o aumento substancial de recursos no que se refere ao compromisso da União, ampliando o aporte, a título de complementação, de cerca de $\mathrm{R} \$ 500$ milhões, tomando-se como base os valores do Fundef, para cerca de $\mathrm{R} \$$ 5 bilhões de investimento ao ano, a partir de 2009. O outro diz respeito ao fato de que houve a institucionalização de um fundo único para toda a Educação Básica e não apenas para o Ensino Fundamental.

Ainda no plano dos avanços, cabe mencionar o capítulo VI da Lei $\mathrm{n}^{\circ}$ 11.494/2007, que versa sobre o controle social dos recursos do Fundo por meio de conselhos instituídos para esse fim. O reconhecimento deste aspecto deve-se a inclusão da representação de sujeitos sociais vinculados à escola, garantindo-se a participação de pelo menos dois pais e dois estudantes, além de um representante dos conselhos tutelares nos conselhos de âmbito municipal. Há de se convir que a legislação também estabelecesse uma série de impedimentos que atinge parentes de membros do Executivo, prestadores de serviços, pais que ocupem cargos ou funções de confiança quanto à participação nesses conselhos, norma igualmente válida para os Conselhos Municipais de Educação (FUNDEB, § $2^{\circ}$ do art. 37).

Contudo, há limitações no Fundeb que inclusive já se verificava no Fundef. O cerne desse aspecto são os problemas que ainda persistem no plano intergovernamental. Sobre essa matéria, Abrucio (2010) pondera que esses Fundos conseguiram dar mais recursos aos governos que se responsabilizam pela política, mas mexeram pouco com as desigualdades regionais que marcam a federação brasileira. Para o autor, seria necessário que a União não só complementasse o dinheiro que falta para chegar à meta básica, mas que também fizesse política redistributiva. Caso contrário, "a equalização se dá num patamar mínimo, e as redes dos estados mais ricos tendem a ter uma diferença substancial de condições em relação aos demais" (ABRUCIO, 2010, p. 64).

Portanto, muito embora o Fundeb represente um avanço ante o Fundef, ao resgatar o conceito de Educação Básica e ao fortalecer o controle social, temse a reedição da desigualdade quanto às condições de atendimento às demandas educacionais no País, uma vez que em ambas as experiências de fundos contábeis a ação redistributiva é limitada ao âmbito de cada Estado, o que fica devendo quando se toma como referência de pacto federativo, a colaboração em que se 
tem por perspectiva a consolidação de um paradigma de qualidade para educação, válido para todo o território nacional, sobretudo num País como o nosso em que se verificam enormes diferenças, do ponto de vista da capacidade financeira, entre os Estados e entre Municípios de cada unidade federativa.

Pinto (2007) apresenta dois principais problemas desta política de fundos que explicitam a ausência de enfretamento das desigualdades regionais: 1) a inexistência de um valor mínimo por aluno que assegure um ensino de qualidade e que impeça as disparidades regionais; 2) embora o fundo seja único no âmbito de cada unidade da Federação, os alunos permanecem atendidos por duas redes distintas, com padrões de funcionamento e de qualidade distintos e que dificilmente conseguem estabelecer um regime de colaboração.

Há aqui a razão que torna plausível a inferência das considerações de Gomes (2000) sobre a projeção das matrículas na Educação Básica brasileira, visto que o aumento do público do Ensino Médio, assim como a redução no nível fundamental tem consequências diretas para as finanças estaduais e municipais respectivamente. Ainda que se tenha como referência o valor mínimo por aluno, o que pressupõe a adequação do provimento financeiro das demandas assumidas pelo critério de equidade, a garantia de condições objetivas para a inserção, permanência e bom desempenho escolar, no novo quadro do Ensino Médio, mas também na Educação Infantil e no Ensino Fundamental, exige a negociação de uma política de infraestrutura e de serviços que favoreça as especificidades de cada etapa da educação escolar, inclusive de arquitetura apropriada, além de recursos de apoio didático em conformidade com as práticas pedagógicas desenvolvidas em cada nível e modalidade de ensino. Trata-se de um conjunto de intervenções que interessam tanto aos Estados quanto aos Municípios, uma vez que a qualidade da ação educativa que é promovida durante uma determinada fase da escolarização tem, necessariamente, repercussões nas demais.

Cabe ressaltar que as expectativas que se lançam sobre o Fundeb, especialmente no que concerne à diminuição da desigualdade entre a rede estadual e as redes municipais de cada estado, devem ser tratadas conjuntamente com o desafio que é posto ao acompanhamento do financiamento da educação em geral. Sobre esse assunto, Davies (2006) afirma que a exigência constitucional de aplicação do percentual mínimo dos impostos tem sido burlada sistematicamente de inúmeras maneiras, inclusive pelo governo federal, no cálculo da complementação legalmente devida para o Fundef, "o que permite concluir que não adianta criar fundos ou até aumentar recursos para a educação se não houver garantia de que serão aplicados nos fins devidos" (DAVIES, 2006, p. 770-771).

Tal observação recai sobre o papel dos sistemas de educação nessa nova conjuntura de gestão educacional em que os problemas quanto à físcalização do cumprimento dos investimentos constitucionais em educação são de domínio público, o que impõe o desafio do controle social sobre o uso das verbas da educação, algo que os conselhos do Fundef não cumpriram de forma satisfatória. Sendo assim, exige maior articulação entre os partícipes dos sistemas, daí nos 
referirmos ao Poder Local com o sentido de Estado ampliado em que a sociedade civil é parte intrínseca, portanto, para além da representatividade governista local, no sentido de tornarem as condições objetivas, anunciadas pelo Fundeb, favoráveis à melhoria da qualidade da educação pública em todos os seus âmbitos.

Quer se afirmar com isso que a referência aos sujeitos coletivos perpassa também a imprescindibilidade do exercício de sua função precípua de controle social. No que diz respeito às finanças da educação no Município, faz-se urgente um acompanhamento mais criterioso da implementação dos recursos vinculados a despesas definidas como de Manutenção e Desenvolvimento do Ensino - MDE ${ }^{1}$, que não podem ser confundidas com as despesas que a Secretaria de Educação nomeia como pertencentes à educação. A cautela que se procura resguardar com a efetiva ação de controle social deve-se ao conhecimento de prejuízo para a MDE perpetrado pelo modo como os governos classificam, de forma irregular, tais investimentos ${ }^{2}$.

\section{Considerações finais}

O exemplo mais evidente de exercício de colaboração na educação brasileira tem sido as políticas de fundos contábeis. Contudo, se por um lado é justo o reconhecimento do caráter imprescindível dos fundos no sentido da possibilidade de intervenção provisória nos desafios que estão postos para o setor, por outro lado, sua existência deve suscitar a defesa por algo condizente com a essência processual com que a educação se identifica. (PINTO, 2007, p. 881), referindo-se ao cunho transitório do Fundeb, afirma que

[...] montou-se uma bomba de efeito retardado com data certa para explodir: 31 de dezembro de 2020, quando finda o Fundeb. Se nenhuma medida de caráter permanente for tomada neste ínterim, o país viverá naquela data uma grave crise no pacto federativo, pois os municípios ficarão com um número de alunos muito superior à sua capacidade de financiamento.

Nossa conclusão toma por base dois aspectos levantados por Pinto (2007). O primeiro diz respeito à chamada de atenção em tom de convocação do Estado e da sociedade civil organizada para que se busque uma medida de caráter permanente, ainda durante o período de vigência do fundo. Trata-se de uma força-tarefa empreendida a partir do entendimento de que os fundos, por um lado, salvaguardaram a sobrevivência do sistema de financiamento da educação, de tal forma que sua permanência deveu-se, também, pelo clamor social que, mesmo identificando suas falhas num período de dez anos (período de vigência do Fundef), ainda assim recorre às lideranças governistas para a sua permanência em caráter extensivo ao conjunto da Educação Básica. Por outro lado, os próprios limites apresentados pela política de fundos têm instigado o debate sobre as contrapartidas necessárias no sentido de se construir mecanismos não apenas de natureza estritamente contábil, mas, sobretudo, de acompanhamento e controle social sobre o que se planeja e investe em educação pública. 
O segundo aspecto, relacionado à citação do autor, coaduna-se com a defesa de que o próprio Fundeb serve de inspiração para o que se pretende instituir como duradouro na gestão dos sistemas educacionais. É possível exibir esse juízo por compreendermos que as regras, definidas para a regulação da parcela de complementação da União, têm como prerrogativa a fixação anual deliberada por uma comissão intergovernamental. Esta exigência corresponde ao que se vislumbra nas relações federalistas. Ainda sobre a distribuição da parcela de recursos da complementação aos fundos de âmbito estadual, merece menção o art. $7^{\circ}$, da Lei $\mathrm{n}^{\circ} 11.494 / 2007$, quando relaciona como requisitos para tal cumprimento legal tanto a apresentação de projetos em regime de colaboração por Estado e respectivos Municípios ou por consórcios municipais quanto à vigência de plano estadual ou municipal de educação aprovado por lei.

Pode-se afirmar que o exemplo que a política de financiamento apresentada guarda coerência com o debate sobre federalismo e Regime de Colaboração no Brasil, entendendo-se que os desafios que emanam da experiência com os fundos de natureza contábil têm contribuído para o provimento de uma agenda transitória para o setor, mas também têm suscitado a discussão sobre o valor do investimento a ser garantido para se atingir a totalidade do gasto com a Educação Básica no País, incitação que deve estar imbricada com as lutas pela redução das desigualdades entre os entes de poder federado.

\section{Referências}

ABRUCIO, F. L. A dinâmica federativa da educação brasileira: diagnóstico e propostas de aperfeiçoamento. In: OLIVEIRA, R. P.; SANTANA, W. (Org.). Educação e Federalismo no Brasil: Combater as desigualdades, garantir a diversidade. Brasília: UNESCO, 2010.

BRASIL. Ministério da Educação. Lei n. 10.172, de 09 de janeiro de 2001. Aprova o Plano Nacional de Educação e dá outras providências. Diário Oficial da União, Brasília: 10 jan. 2001. 2009.

Constituição da República Federativa do Brasil: 1988. Brasília: Senado Federal,

Emenda constitucional n. 59, de 11 de novembro de 2009. Modifica os artigos 76 do Ato das Disposições Constitucionais Transitórias, para reduzir, anualmente, a partir do exercício de 2009, dá nova redação aos incisos I e VII do Art. 208, dá nova redação ao $§ 4^{\circ}$ do art. 211 e ao $\S 3^{\circ}$ do art. 212 e ao caput do art. 214, com a inserção neste dispositivo de inciso VI.

Lei de Diretrizes de Bases da Educação Nacional. Lei no 9394/96. Brasília, 2008. Disponível em: <http://portal.mec.gov.br/seesp/arquivos/txt/lei9394_ldbn1.txt>. Acesso em: 03 mar. 2008.

BRASIL. Ministério da Educação. Lei n. 11.494/. Regulamenta o Fundo de Manutenção e Desenvolvimento da Educação Básica e de Valorização dos Profissionais da Educação FUNDEB. Diário Oficial da União, Brasília: 21 jun. 2007.

Emenda Constitucional $n^{\circ}$ 14/1996. Modifica os artigos 34, 208, 211 e 212 da Constituição Federal e dá nova redação ao art. 60 do Ato das Disposições constitucionais Transitórias. Presidência da República. Casa Civil. D.O.U. 13.9.1996 Disponível em: <http://www.planalto.gov.br/ccivil_03/constituicao/emendas/emc/emc14.htm>. Acesso em: 7 mar. 2012. 
GURY, G. R. J. Gestão democrática dos sistemas públicos de ensino. In: OLIVEIRA, Maria A. Monteiro (Org.). Gestão educacional: novos olhares, novas abordagens. Petrópolis: Vozes, 2005.

. A questão federativa e a educação. In: OLIVEIRA. R. P.; SANTANA, W. (Orgs.). Educação e Federalismo no Brasil: combater as desigualdades, garantir a diversidade. Brasília: UNESCO, 2010.

DAVIES, N. FUNDEB: a redenção da educação básica? Educação \& Sociedade. Campinas, v. 27, n. 96, 2006.

. Conselhos do FUNDEF: a participação impotente. Ensaio: avaliação, políticas públicas e educacionais. Rio de Janeiro, v. 11, n. 41, out./ dez. p. 502-517, 2003.

DOURADO, L. F. Plano Nacional de educação: avaliações e retomada do protagonismo da sociedade civil organizada na luta pela educação. In: FERREIRA, N. S. Carapeto (Org.). Políticas públicas e gestão da educação: polêmicas, fundamentos e análises. Brasília: Líber Livro, 2007.

(Org.). Plano Nacional de Educação (2011-2020): avaliação e perspectivas. Goiania,

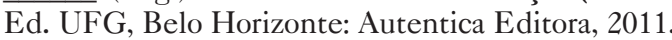

FRANÇA, M. Sistema Nacional de Educação: financiamento, valorização dos profissionais da educação básica e perspectivas do PNE (20 I 1-2020) In: FRANÇA, M. (Org.). Sistema Nacional de Educação e o PNE: diálogos e perspectivas. Brasília: Liber Livro/ UFRN, 2009.

FRANÇA, E. Regime de colaboração sem subordinação ou hierarquia. Revista Educação Municipal, n. 5. Brasília: UNDIME, 2002.

OLIVEIRA, R. P.; SOUSA, Sandra Z. Introdução: o Federalismo e sua relação com a educação no Brasil. In: OLIVEIRA, R. P.; SANTANA, W. (Org.). Educação e Federalismo no Brasil: combater as desigualdades, garantir a diversidade. Brasília: UNESCO, 2010.

OLIVEIRA. R. P. O financiamento da educação. In: OLIVEIRA. R P.; ADRIÃO. Theresa (Orgs.). Gestão, financiamento e direito à educação: análise da constituição federal e da LDB. 3. ed. São Paulo: Xamã, 2007.

PINTO, J. M. de R. A política recente de fundos para o financiamento da educação e seus efeitos no pacto federativo. Educação \& Sociedade, 2007, v. 28, n. 100.

SOUZA, D. B. de; RAMOS, M. N. DELUIZ, N. Regime de colaboração entre os entes federados e a cobertura da educação profisssional municipal. Cadernos ANPAE n. 4, Porto Alegre: ANPAE, 2007.

SARI, M. T. Regime de colaboração intergovernamental na educação: a experiência pioneira do rio Grande do Sul. Cadernos ANPAE, n. 4, Porto Alegre: ANPAE, 2007.

\section{Notas}

${ }^{1}$ A LDB/1996 define, em seus artigos 70 e 71, o que são e não são despesas em MDE.

${ }^{2}$ Davies (2003) disserta sobre o problema da inclusão ilegal de despesas em MDE com base em análise de dados emitidos pelo Tribunal de Contas do Rio Grande do Sul. O estudo relaciona 37 tipos de despesas ilegais que os governos gaúchos (segundo o autor, isso provavelmente valeria também para outros governos estaduais e municipais) consideravam de MDE. Dentre os exemplos que atestam tal irregularidade, destacam-se: "construção de ginásio ou centro esportivo comunitário, pavimentação 
de ruas de acesso ou fronteiriças a prédios/instalações escolares, construção de abrigos em paradas de ônibus nas zonas rural e urbana, realização de eventos como festivais musicais e de teatro, shows, rodeios, construção de poços tubulares profundos ("artesianos")" (DAVIES, 2003, p. 154).

* Edson Francisco Andrade - Professor Doutor da Universidade Federal de Pernambuco, Recife, Pernambuco, Brasil.

\section{Correspondência}

Edson Francisco Andrade - Universidade Federal de Pernambuco, Centro de Educação.

Rua da Arquitetura, S/N, Cidade Universitária

CEP: 50740-550 - Recife, Pernambuco, Brasil.

E-mail: edsonprofessor@uol.com.br

Recebido em 10 de agosto de 2012

Aprovado em 04 de março de 2013 
